\title{
"It fitted in with our lifestyle": An investigation into episodic volunteering in the tourism sector
}

\section{Introduction}

Volunteers are vital to the delivery of visitor services to tourists across Australia. Without them many visitor attractions, events and visitor information centres would cease to operate (Jago \& Deery, 2002; Holmes \& Smith, 2009) or would offer, in the case of airport meet and greeters, for example, a substantially reduced service. Even more significant are the emergency services provided by volunteers, such as surf life-saving, for which many tourists owe their lives.

Yet, researchers have documented how volunteering is changing in response to economic, political and societal forces (Merrill, 2006; Rochester et al, 2010). In particular, they have identified the rise of episodic and more individualistic forms of volunteering and the associated challenges these bring for volunteer program managers (Macduff, 2005; Hustinx \& Lammertyn, 2003; Hustinx \& Meijs, 2011). However, we still know very little about how both traditional, regular volunteers engage in sustained volunteer activity and newer, episodic volunteers fit their volunteer activities within their often busy lives.

This paper uses interviews with both regular and episodic volunteers in tourism organisation's to investigate why individuals choose episodic or sustained forms of volunteering in order for managers to design recruitment and retention policies which will meet both the organisation's and the volunteers' changing needs. This paper also identifies opportunities and threats for tourism organisations in response to the growth of episodic volunteering. 
The paper begins by examining the phenomenon of episodic volunteering and the social and economic forces which are shaping this growing form of participation. The paper then reviews extant research on why individuals choose to volunteer episodically and discusses what this trend may mean for tourism organisations. Next, the methods and fieldwork undertaken for this paper are described and the findings are presented, drawing out implications for practice.

\section{Literature review}

\section{Changing participation in volunteering}

Evidence suggests that participation in volunteering has changed, at least in Western countries (Rochester, Ellis Paine \& Howlett, 2010). While it is difficult to document trends as national surveys do not always use comparable methods (Wilson, 2012), research in the UK has found that although the proportion of the population who volunteer is increasing (Cabinet Office, 2013), there is a reduction in the number of hours volunteered (Low et al, 2007). Similarly, survey data from Australia shows that more people are volunteering but for less time (ABS, 2011) with 'median hours volunteered', an important indicator of the health of volunteering, in long-term decline (FaHCSIA, 2008). This trend has also been documented in the USA (Rotolo \& Wilson, 2007), although overall participation in volunteering remains stable (Corporation for National and Community Service, 2014). Finally, a study of volunteer participation across Europe has pointed to the increased number of people involved in short term episodic volunteering (McLoughlan et al., 2011).

This trend is a particular challenge for organisations which need regular volunteers. The majority of organisations in Australia already need more volunteers to meet demand for their 
services (Volunteering Australia, 2011). If volunteer hours reduce then more volunteers will be needed to cover the same services, which is likely to increase the costs associated with recruitment and supervision. Researchers have identified a number of factors which may have impacted on changing participation in volunteering. Current trends overwhelmingly suggest that work-life balance issues and the demands they place on people's time affect the hours both current and potential volunteers can commit to volunteering (Gaskin, 2003; Merrill, 2006).

Data on volunteer participation shows that available time is the key influence on propensity to volunteer and factors such as paid work, family commitments and leisure activities affect the amount of time available for volunteering for both current and potential volunteers (Merrill, 2006; Musick \& Wilson, 2008). Lack of extra time is a key barrier to volunteering among young people, those in employment and those with high household incomes (McClintock, 2004; Rochester et al., 2010). Western countries have ageing populations, with growing numbers of retired but active individuals (Australian Government, 2010; Office of National Statistics, 2011). While this would suggest that there is a growing recruitment pool for volunteers, this segment of the population is also more affluent and has many more opportunities and demands on their free time in retirement. Competition for volunteer services is fierce, with volunteer-involving organisations needing to adapt as individuals, especially baby-boomers and Millennials, become more discretionary about where they volunteer, for how long, and in what types of roles (Winterton, Warburton \& Oppenheimer, 2013). Volunteer organisations have to compete with family commitments, work, increased mobility, with volunteers taking more and longer holidays and many other leisure possibilities for their volunteers. 
Since the mid-1990s there has been acknowledgment of more disparate forms of commitment and volunteering (Hustinx \& Lammertyn, 2004; Brudney 2005), reflecting wider shorttermism in employment relationships generally or what Watson, Buchanan, Campbell and Briggs (2003) describe as fragmentation in working and personal life. Evidence suggests that as people perceive they have less time outside of work, they have typically adopted more individualized leisure pursuits (Nichols \& Holmes, 2013). Volunteering has been conceptualised as leisure (Rochester, Ellis Paine \& Howlett, 2010) and Stebbins' leisure theory provides a means for classifying both sustained volunteering and episodic volunteering as forms of leisure. Traditional, sustained volunteering has been examined as a form of serious leisure for a number of years (Stebbins, 2007). Stebbins has also introduced the concept of 'project-based leisure' (2005), which can be a short term but 'moderately complicated' activity. Project-based leisure is similarly demanding as serious leisure but lacks the ongoing career aspect and this concept reflects the rise of more individualistic approaches to leisure. Similarly, volunteering has been theorized as occasional, episodic and regular. A one-off volunteer tourism holiday could be described as occasional; assisting at the same event each year as episodic, and helping at a visitor centre each week as regular.

Changing participation in volunteering reflects the rise in individualistic approaches to work and leisure (Hustinx \& Lammertyn, 2004; Hustinx \& Meijs, 2011). Hustinx terms this the 'new volunteerism' and contrasts it with 'classic volunteerism' not simply based on the hours and frequency of the volunteer commitment but also on how this influences the choice of organisation, cause or activity and the relationship with the beneficiary. The traditional, classic volunteer bases many of these choices on their traditional cultural identity, exhibiting substantial loyalty to the organisation and fitting in with the organisation's needs. In contrast, the new volunteer has weaker ties to the organisation and balances the organisation's needs 
with their own preferences, seeking and expecting a reciprocal relationship with the organisation where each benefits (Hustinx \& Meijs, 2011).

External factors are also likely to have shaped attitudes towards volunteering, not least the effort by Western neo-liberal governments to use volunteering as a means to fill the gaps between public and private sector provision of services (Pick, Holmes \& Brueckner, 2011). Governments and educational institutions have also encouraged more instrumental motivations towards volunteering by emphasizing the benefits of volunteering to individuals in terms of increasing their employability (Haski-Leventhal et al, 2008; McLoughlan et al., 2011)

The new volunteerism coincides with a series of trends offering alternative forms of volunteering to the traditional model. These include virtual or online volunteering, corporate volunteering, international volunteering, family volunteering, and episodic volunteering. The latter is the focus of this paper and presents potential problems and possible opportunities for volunteer-involving organisations (Rochester, et al., 2010).

\section{The growth of episodic volunteering}

Episodic volunteering is seen as a major current and future trend (Brudney, 2005; Merrill, 2006; Wilson, 2012) and Meijs and Brudney (2009) postulate that episodic volunteering may account for as much as half of all voluntary activity in the USA and in other Western countries. While Macduff (1991) first coined the term 'episodic volunteering' to refer to oneoff volunteering assignments which offer a flexible relationship with an organisation, surveys were reporting that organisations were struggling to recruit traditional volunteers in the $1980 \mathrm{~s}$ (Macduff, 2005). Hustinx and Lammertyn (2004, p. 568) use the term 'distant' to describe 
volunteer participation that is characterised by loose, infrequent, short-term and activitiesbased involvement. This changing approach to volunteering has also been classified as 'cause-driven' in contrast to the more traditional 'time-driven' volunteers, who are looking for something to fill free time (Evans \& Saxton, 2005). More recently, it has been recognised that whilst the volunteering activities may be short-term the volunteers may return or reengage with a single organisation in a series of episodic relationships (Handy et al., 2006; Macduff, 2005). Bryen and Madden (2006) use the term 'bounce-back' to describe this situation, and draw parallels with the factors influencing retention of continuous volunteers.

Episodic volunteering therefore can involve temporary, episodic and occasional time commitments. Macduff (2005) describes different forms of episodic volunteering based on their time commitment: temporary episodic volunteer - who offers just one short volunteer commitment; interim volunteer - who is involved on a regular basis over a short, finite period of time; and occasional episodic volunteer - who provides short periods of service on an infrequent basis. A further typology is offered by Handy et al (2006) who distinguish between habitual episodic volunteers who volunteer for multiple episodic opportunities on a continual basis, and genuine episodic volunteers who volunteer for two or fewer volunteer episodes in a year. Stebbins conceptualisation of project-based leisure resonates with episodic approaches to volunteering. Like episodic volunteering, project-based leisure can be both one-off or occasional and Stebbins (2007) specifically uses the example of volunteering for an event or festival to illustrate the concept.

Episodic volunteering per se has received limited attention from academic researchers, with much of the extant research dating from the mid-2000s. However, there has been a substantial growth in studies of specific forms of episodic volunteering. Examples include event and festival volunteers, volunteer tourism and disaster volunteering. Smith et al (2014) have 
documented the rise in research on event volunteers over the past decade, with a focus on mega events such as the 2012 London Olympics and Paralympics, which involved over 70,000 episodic volunteers. Tomazos and Butler (2009) investigated the scale of episodic volunteer tourism and found a nearly $500 \%$ increase in the number of projects available between 2004 and 2007. They also noted a substantial increase in volunteer projects associated with disasters, particularly in countries affected by the 2004 Asian Tsunami as well as the USA, following Hurricane Katrina. These studies show that there is growing demand for these shorter, fixed-term volunteer experiences.

Organisations are responding to the growth in episodic volunteering in different ways. The Ronald MacDonald House, for example, offers two volunteer programs: one for traditional volunteers and one for episodic volunteers (Hustinx et al, 2008). Organisations that offer genuinely episodic opportunities for volunteers are considered to be more successful in both recruiting and retaining volunteers (Taylor et al, 2008). While the challenges of meeting the needs of the new volunteer are much discussed by practitioners, surprisingly there has been little academic attention paid to this phenomenon (Taylor et al, 2008).

\section{Why do people choose to volunteer episodically?}

There is a substantial body of work about volunteer motivation. Previous research on volunteer motivation can be divided into three groups: studies which seek to devise typologies of volunteers based on their motivations (for example Parker, 1997); studies which conceptualise groups or dimensions of motivators (for example, Snyder et al, 2000); and surveys which simply seek to generate lists of motivators (for example ABS, 2007). 
The most widely applied theory of volunteer motivation is the Volunteer Functions Inventory (VFI) (Snyder et al, 2000), which provides a framework of six motivations for volunteering:

- Values (e.g. reinforcement or expression of personal values)

- Enhancement( e.g. learning)

- Social (e.g. being part of a group)

- Career (e.g. work skills and contacts)

- Protective (e.g. increasing confidence)

- Understanding (e.g. personal growth)

The theory behind the VFI is that while all motivations fit within these six motivations, each volunteer will experience different patterns of motivation even if they are participating in the same activity.

The VFI provides a useful and widely used framework for volunteer motivation (Wilson, 2012) and has been applied to both ongoing and episodic forms of volunteering (for example, Houle et al., 2005 and Brayley et al., 2014). The VFI seeks to identify why people choose to volunteer per se rather than why they choose to volunteer for a specific role or organisation. In addition, there has been limited research on how the motivations of different groups of volunteers may vary based on their time contribution. Hustinx and Lammertyn (2004) proposed that episodic volunteers have different motivations and are seeking a different experience from traditional volunteers. The few studies that do examine episodic volunteers have suggested that they are more motivated by values and more idealistic than traditional volunteers and are still very committed to the cause and/or organisation (Handy et al, 2006; Hustinx et al, 2008). Indeed, Hustinx et al's (2008) comparative research at the Ronald MacDonald House between traditional and episodic volunteers found that the episodic volunteers were often less rewarded and received less recognition than regular volunteers and 
that tangible rewards were less important to this group. In addition, while the episodic volunteers were performing less complex tasks, they still wanted to receive sufficient training to be able to perform these tasks well. It seems that for episodic volunteers, giving less time to an organisation does not mean giving less commitment to the organisation's aim or cause.

Most research on volunteer participation examines people's participation in one organisation. Yet qualitative studies have identified that individuals can have a portfolio of voluntary activities (Holmes \& Slater, 2012) and participate in these in different ways. The Pathways to Participation project in the UK (Brodie et al, 2011) used in-depth interviews to examine how people participate in community and civic activities, including volunteering. The project identified three patterns of participation. Individuals may have: core and peripheral activities; a range of limited but connected commitments; or a series of unconnected forms of participation. Individuals may be, therefore, episodic volunteers at one organisation but regular volunteers at another.

It is clear that there remain many unanswered questions about episodic volunteers. Why do people volunteer episodically? Is it simply because they do not have the time to do something regularly? Is it because of their lifestyle? Is it because they have different expectations and motivations from regular volunteers? Is volunteering for them a reciprocal arrangement rather than a gift of time? These questions feed into this paper's broader aim, which is to identify why individuals choose episodic or sustained forms of volunteering in tourism organisations.

\section{The implications of episodic volunteering for the tourism sector}

The growth in episodic forms of volunteering has clear implications for volunteer-involving tourism organisations. The particular challenge is that many tourism organisations require 
volunteers during the day to provide often essential services to tourists (Holmes \& Smith, 2009). These include visitor information centres, visitor attractions, and meet and greet programs. These organisations have traditionally relied on retired classic volunteers, who are available during these times and who are prepared to make a regular commitment to the organisation over a period of years. If this source of volunteers dries up, this will lead to operational challenges including having to reduce visitor services or even close these entirely, as documented at four visitor attractions in southern England (Holmes, 2008). Visitor attractions in particular require their volunteers to complete significant training programs and can also lead to substantial out of pocket costs for volunteers (Homes, 2009). This is neither cost effective for the organisation nor attractive to potential episodic volunteers.

However, there are also opportunities for tourism organisations. Tourism is seasonal and would seem to have a natural affinity with interim volunteering. Events and festivals, both one-time and regular, offer opportunities for temporary episodic volunteers and bounce back volunteers to become involved. Tourism organisations, therefore, could be well-placed to benefit from this new approach to volunteering.

This paper seeks to extend our understanding of episodic volunteering by investigating two samples of volunteers (one episodic and one regular) from programs within the tourism sector and examining their motivations, experiences and commitment, and seeking to identify differences and commonalities between these two forms of volunteering.

\section{Methods}

While the rise in episodic volunteers has been much discussed, there are few empirical studies examining this group. The study of episodic volunteers is still exploratory in nature 
and a fuller understanding of episodic volunteering is needed along with why and how the experience may be different from regular volunteering. At this stage a qualitative approach is the most appropriate for eliciting data on volunteers' subjective experiences (Bryman, 2004). This paper seeks to identify possible differences between the experiences of episodic volunteers and those of regular volunteers in similar contexts. Therefore an in-depth interview method was selected and interviews were conducted with 20 volunteers: 10 episodic volunteers and 10 regular volunteers. Volunteering is often a social activity (Holmes \& Smith, 2009) so eight of the interviewees were married couples who volunteered together and were interviewed together.

The interview schedule for both groups of volunteers sought to uncover the reasons behind the respondents' decisions to volunteer in their specific role. Few specific questions were asked as the interviewer sought to encourage respondents to talk about their experiences in their own words and at their own pace; rather, prompts were used to elicit further details (Bryman, 2004; Kvale \& Brinkman, 2009). Specific questions included asking the respondents to describe their volunteer role, how they first became involved in that role, whether their role had changed since they started volunteering (including the time commitment), and why they continue to volunteer. Respondents were also asked about how volunteering fits in with their other life commitments, including paid work, family, leisure and other volunteering. These questions helped to elicit reasons behind the decision to volunteer regularly or episodically.

The volunteers were purposively recruited from volunteer programs which offered both regular and episodic volunteer opportunities within the tourism sector. Purposive sampling enables the researcher to ensure that the range of characteristics among the participants which 
are needed to answer the research questions are included in the sample (Bryman, 2004). In this study purposive theoretical sampling was employed; that is the interviewees were recruited iteratively, organisation by organisation, until there was sufficient data to answer the research question (King, 1998). The volunteer programs were identified through web research. As detailed in Table 1, some programs had only regular or episodic volunteers while others had both. The volunteer program manager was initially contacted and served as a gatekeeper to identifying potential respondents by circulating information about the project to potential interviewees. Willing respondents were asked to contact the researcher directly. As purposive sampling is iterative (Mason, 2002), not all organisations were contacted at the same time and it proved challenging to recruit episodic volunteers using this method. As a result, the annual sports event was the final program to be included in this study and was specifically included as this would provide a gateway to episodic volunteers.

Interviews lasted between 30 and 60 minutes and were held at a place and time convenient to the participants (King \& Horrocks, 2010), so interviews were held either at the homes of participants, at a local café or at the volunteer organisation's offices. The interviews were all conducted between 2008 and 2009 in Western Australia. University ethics approval was obtained prior to beginning the fieldwork and all respondents were asked to give informed written consent to participate in the project following the procedures of the National Statement on Ethical Conduct in Human Research (2014). All names used in the reporting of the data are pseudonyms to maintain the confidentiality of the respondents.

The programs from which the volunteers were recruited included an annual sports event; campground hosts; tour guides at an off-shore island; tour guides at a zoo; meet and greet 
volunteers from an airport; and a domestic volunteer tourism program. These volunteer programs were selected as representing a cross-section of tourism volunteer programs.

All the volunteer programs are located in Australia. Further details about the programs are presented in Table 1:

\section{INSERT TABLE 1 ABOUT HERE}

The domestic volunteer tourism program, the campground host program, and the island holiday guiding involve volunteers spending time away from home, with the volunteers travelling to a destination to volunteer. The island tour guides and airport meet and greeters could choose to volunteer either episodically or regularly, or a combination. At other programs, such as the sports event or the zoo, it was only possible to volunteer either episodically or regularly. Table 2 provides respondent's details including program, usual time commitment, gender, and work status. Both groups included a mixture of male and female respondents, and retirees and people in paid work, although both groups of volunteers, episodic and regular, were predominantly female and retired.

\section{INSERT TABLE 2 ABOUT HERE}

The interviews were all audio-recorded, transcribed, and analysed thematically with the assistance of Nvivo 10 following Miles and Huberman's guidelines (1994). The data were coded using the categories of the Volunteer Functions Inventory (Snyder et al, 2000) - that is career, enhancement, material, protective, social, understanding and values, with a further category of tourism specific motivations which included interest in the place and wanting to 
promote the place or spend time there as this emerged as a major theme from the data. A matrix was also used to compare the time contributions of each of the participants and comments, which related to the temporal nature of their volunteering, were classified into an additional node.

Data were coded by two researchers, particularly looking for patterns in the motivations and experience of the volunteers within and across each group. The interviews were first coded by one researcher and code-checked by a second researcher to ensure consistency (Miles \& Huberman, 1994). A summary of the findings was sent to each participant and they were invited to comment, which serves as a process for ensuring the authenticity of the analysis as representing the participants' perspectives (King \& Horrocks, 2010). No comments were received other than an appreciation of being able to see the outcome of the research.

\section{Findings}

The findings are presented in two sections. The first section examines the motivation of the volunteers in this study, using the framework of the VFI. The second section examines the temporal nature of their voluntary activity. As the findings demonstrate these two factors were closely interlinked. As this is an exploratory study, the findings present the respondents' subjective views of their volunteer experiences and the context of their volunteering is important in understanding their views.

\section{Motivation}

The two groups typically had become involved with their organisations through different avenues. The regular volunteers were most likely to have been invited by a friend to join the volunteer group or a family member suggested it to them. For example, Barbara, a regular 
zoo volunteer, was actually volunteered by her daughters, who filled in the application form and posted it on her behalf. Kay was feeling unhappy and lonely after her children left home when her son saw a television advert about the airport meet and greet program and urged her to call the volunteer coordinator.

In contrast, most of the episodic volunteers actively sought out their placement because of their intrinsic interest in either the location or the actual activity.

"We saw it advertised and we had wanted to do volunteer work since we finished work and basically just give something back, and the reason we looked at volunteer, well visiting volunteers is the fact that you could go and volunteer at a place, hit a place and then leave." Delia and Alan, domestic volunteer tourists.

There were of course exceptions in both groups. Rebecca, a sports event volunteer became involved initially as her sports club was asked to supply volunteers for the event and Philip and Kate, two regular island guides, were purposefully looking for something to do after migrating to Australia in retirement.

Both the regular volunteers and the episodic volunteers had mixed motivations for volunteering although both groups wanted to do something worthwhile - a useful activity that would benefit someone other than or in addition to themselves:

"Since we retired once we got settled here and did all the things that immigrants do, buy property and all the rest of it we began to look around for something to do giving back to the community is the way we always looked at it." Philip and Kay, regular island guides

The regular volunteers frequently cited social motives as a reason to keep volunteering. This seems to be a function of regular volunteering, particularly for zoo volunteers who are assigned a regular volunteer shift on the same day. Mike describes going in for his shift at the 
zoo 30-45 minutes early so he can have a coffee with the other volunteers on his regular days and he says: "I always find the Friday people the best". The regular volunteers often met up outside of the volunteer program for social occasions, such as theatre visits or Melbourne Cup lunches. In contrast, the episodic volunteers were generally not looking for the social contact with other volunteers rather they took their friends or family with them. Liz, an episodic island tour guide, for example went over to the island with the same group of friends each year to do a week long stint. The social contact which these volunteer programs afforded with visitors from all over the world was important to both groups, however, and added to the overall opportunities for the volunteers to meet people.

Two of the regular volunteer programs, the zoo and the island tour guiding program, involved a substantial training element and the regular volunteers frequently cited the opportunity to learn or develop as a significant motivator. The zoo volunteers and island guides in particular described spending their own time outside of the training program, researching information to add to their tours and attending seminars and presentations organised by the volunteer program. This desire to build up knowledge and expertise is more closely aligned with regular rather than episodic volunteering, described by Richard, a regular island guide as "life-long learning" and reflects enhancement motives.

A final motive for the regular volunteers, which is specific to the tourism context, was the opportunity to spend time in a beautiful or special place. Barbara described the zoo as "it's just a really nice place to be", which contrasted with the rest of her week: "this is my stress release day." 
In terms of their motivations, the episodic volunteers were less concerned with learning or social opportunities. Rather, like the regular volunteers, they cited the need for doing something worthwhile and also for their efforts to be noticed, which suggests values motives. Ben and Anne, two domestic volunteer tourists were pleased that the local community appreciated the effort they put into restoring a local heritage centre. Arthur, a campground host, also spoke of the importance of doing something worthwhile with his time:

"People keep saying "What? You do all that work for nothing, you clean that or you repair", well why not? We're pensioners, we live comfortably, we're alright, so why can't we give a little bit back, but there are people who think we are crazy because we do work for nothing"

In contrast to the regular volunteers, the episodic volunteers appeared to be more causedriven. They spoke about having a passion and pride for the cause or the organisation. For example, Liz, an island guide, wanted to show off the island to other visitors and tell them the diversity of activities they can do during their visit. The episodic volunteers also cited enjoyment as a key part of their activity, with Rebecca, a sports event volunteer commenting about how much fun it is to be in the middle of the event. The intensity of the activity seemed to be important and Delia and Alan talked about their domestic volunteer tourism episode as "an experience". These responses suggest both values and understanding motives.

The short term nature of the event or project also gave the episodic volunteers a sense of achievement, which again suggests values motives. In contrast to a regular activity with no defined end, the episodic volunteers could see an event or project through from start to finish. This was cited by several of the episodic volunteers, with Alan (a domestic volunteer tourist) commenting, "I... basically have them a commitment that I'd try and do that task". This also made the project more personal as the volunteers were highly involved at all stages and could 
claim responsibility for the finished project. For example, Rebecca is a team leader at the sports event and manages her team for the whole event and Penny and Arthur completed a number of projects in national parks while volunteering as campground hosts.

It seems that regular and episodic volunteers have different preferences when it comes to the duration of their activities. One regular volunteer Philip, an island tour guide who usually volunteered one day a month, had also volunteered for a week long stint on the island and commented that he would not want to do this again as it was much more intense and harder work. In contrast, Liz, an island guide who only does week long 'holiday guiding', believes that the substantial gaps between each volunteer episode keep her 'fresh'. The choice of time commitment is about more than just availability.

\section{Time commitment}

Regular and episodic volunteers clearly contribute their time in different ways but how did the time contributions between the two groups of volunteers in this study compare? The episodic volunteers contributed between one full weekend and a six month block per year and the median contribution was a two week block. The regular volunteers contributed between two days a week and one day a month and their median contribution was slightly more than once a fortnight as this included committee work in addition to volunteering at the site. Averaged out over a 12 month period, the total time commitments of both groups of volunteers could be similar, but the pattern of volunteering was substantially different.

Both groups of volunteers were asked why they chose to volunteer in this way. The episodic volunteers were very clear that they did not want to make a regular commitment to an organisation. Danielle, a busy single mother with three jobs who works shifts not surprisingly 
commented that "I have a time problem". Her volunteer episode at the sports event comprised of one weekend with some training beforehand but she was volunteering for that entire weekend and camping out overnight at the site.

The retired episodic volunteers did not have the same complex commitments as Danielle but still did not want to be tied down to a regular volunteer role. Delia and Alan, recent retirees, commented that in their perception "Volunteering becomes very regimented and you know you've got to be there every day...then you can 't enjoy your time off'. Instead they chose to volunteer for 68 hours over a two week period, nearly the equivalent of one day a month for a year. This was reiterated by Ben and Anne, who are also retired and like to be able to travel often to visit their children who live overseas. They commented that in their lives "things change all the time" and so they do not want to be tied down.

The episodic volunteers were clearly looking for activities which fit around their lifestyles. Yet this was equally the case with the regular volunteers who also talked about choosing volunteer roles that fitted around their lifestyles. It was just that their lifestyles are different. Kay and Marnie, for example, both had husbands who were still working. They were looking for something interesting and useful to fill their time while their spouses were busy at work. Indeed, it was important for the regular volunteers that their activities did not interfere with family time, particularly the weekends and this meant that episodic volunteering, such as spending a week as an island guide over the school holidays instead of one day a month, was not attractive.

It seemed that a significant influence on the type of volunteering chosen was whether individuals like to plan their lives or prefer to be spontaneous. For example, episodic 
volunteers Ben and Anne viewed regular volunteering as something which obstructed their lifestyle, while regular volunteers Philip and Kate found it made it easier to plan their lives: "It's good because we can do most of the planning ahead...we can fit it around our lives" (Philip, regular island tour guide). Similarly, Delia and Alan, episodic domestic volunteer tourists, commented that they did not want to be relied on by an organisation. In contrast, Barbara, a regular zoo guide, commented that it was easy to change a planned shift by swapping with another volunteer.

Three of the episodic volunteers were working and their decision to volunteer for occasional blocks of time fitted in with their other commitments. The other seven episodic volunteers were retired and had a history of regular volunteer work and other community activities while they were working, but in retirement they had made a decision to change their lifestyles, particularly to enable lengthy periods of travel. Some did other episodic volunteering and others did regular volunteering when they were at home. This lifestyle change is best encapsulated in the case of Keith, a campground host. Keith was unhappy in retirement where he lived and made the decision with his wife to sell their house in the city and buy a large block of land in the country where they built a shed for their caravan. For six months every year they travel around, stopping off for lengthy periods to volunteer as campground hosts.

Interestingly though, a couple of episodic volunteers in this sample actually did have regular volunteer roles at other organisations and indeed some of the regular volunteers also did some episodic volunteering. This could even be at the same organisation. Ellen and Kay, both airport meet and greeters did regular shifts at the airport but also helped out from time to time meeting cruise ship passengers, which was on a more ad hoc basis when they had time 
available. This has not been picked up in previous studies, which only question volunteers about their current role.

\section{Discussion}

Previous research on episodic volunteers has suggested that these are individuals who approach volunteering in a substantially different way to traditional volunteers. Volunteering to them is a reciprocal relationship with the organisation and they are more motivated by causes rather than a desire to help the organisation (Hustinx \& Meijs, 2011). The two groups of volunteers interviewed in this study do have different motivations. The regular volunteers were looking for something worthwhile to fill a portion of their time on a regular basis, for social contact and to have a break from their everyday lives by spending time somewhere completely different in a place for which they have a passion. In terms of the VFI framework, regular volunteers seemed to have enhancement and social motives, which closely links their activities to the serious leisure concept (Stebbins, 2007). The episodic volunteers equally wanted to do something worthwhile with their time, but brought their social contacts with them in the form of family or friends and were more interested in taking on a complete task or project which they could see through to the end. In terms of the VFI, the episodic volunteers seemed to have more values motives.

These findings echo Evans and Saxton's classification (2005) of regular volunteers as 'timedriven' and episodic volunteers as 'cause-driven'. This was particularly the case for the regular volunteers who often began to volunteer with the necessity to fill a regular time slot or fulfil a need such as loneliness after their children had left home or while their spouse was at work. The regular volunteers were also anticipating a longer-term relationship with the 
organisation, particularly the opportunity to build up their knowledge through personal research in addition to the basic training requirements. There are substantial training requirements for the island guides and zoo volunteers which may not be compatible with episodic volunteering. Episodic volunteers could be unwilling to undertake a training program which requires more time to complete than they plan to volunteer and likewise, volunteer program managers may not see the value in investing time and effort training a volunteer who is only planning on contributing on an ad hoc basis. The episodic volunteer projects in this study were perceived by the participants as more exciting than regular volunteering because of the adrenaline and sense of achievement derived from the event or completing the project.

Calculated over the year, the episodic volunteers in this study contributed about the same number of hours as the regular volunteers - and sometimes more - so they were giving the same amount of time, just in a very different way. Of particular interest is that both groups of volunteers viewed the other approach as harder. Regular volunteering is harder to do for an episodic volunteer because they do not want to be tied down to a weekly or monthly commitment, even if it is easy to swap their shift. Episodic volunteering is harder for a regular volunteer because it is a much bigger time commitment in one go and the regular volunteers would rather spread their volunteer hours over a longer time period.

Most of the episodic volunteers could be described as either temporary episodic volunteers domestic volunteer tourists - or occasional episodic volunteers - island tour guides or campground hosts (Macduff, 1991). It is possible to distinguish within the sample of episodic volunteers some habitual episodic volunteers and genuine episodic volunteers (Handy et al, 2006). Danielle, a sports event volunteer, is constrained by work and family and Liz, an 
episodic island guide, was only able to get over to the island during her holidays. Both Liz and Danielle were choosing to volunteer episodically but repeatedly. They could be classified as habitual episodic volunteers (Handy et al., 2006) or bounceback episodic volunteers (Bryen \& Madden, 2006). . Delia and Alan, domestic volunteer tourists who did not want to make regular commitments could be classified as genuine episodic volunteers. However, the sample also included episodic volunteers who were engaged in regular volunteering at other organisations, which suggests that patterns of participation are more personal, as suggested by the Pathways to Participation project (Brodie et al, 2011). The sports event volunteers and some of the campground hosts could also be described as bounce-back volunteers (Bryen \& Madden, 2006). Yet all of these terms seem to fail to capture both the essential nature of these episodic volunteers, for example the sports event could not take place without them, and the demanding nature of the volunteer episode.

The VFI was used as a framework for analysing the motives of the different volunteers in this study and helped identify dominant motives among regular volunteers (social and enhancement) and episodic volunteers (values). However, the temporal nature of the volunteer activity was a substantial motivator for all the volunteers and they were all looking for a role which fitted in with their lifestyle, whether it was regular or episodic. While studies of episodic volunteers suggest that they have different motives to regular volunteers (Hustinx et al., 2008), volunteer motivation theories do not include time - time available or time needing to be filled - as a motive. This is a particular surprise given that lack of time is frequently cited as a barrier to volunteering (Nichols \& Holmes, 2013). This study has highlighted how time availability shapes an individual's choice of volunteer activity. 
It is significant that some of the episodic volunteers in this study are regular volunteers elsewhere and some of the regular volunteers are both regular and episodic volunteers at other organisations. It is also significant that some of the episodic volunteers have become episodic as part of a substantially changed lifestyle in retirement, having previously been involved in regular volunteer activities which fitted in with their working lives. This raises questions about the conceptualisation of episodic volunteering as a new and distinct approach to volunteering. How far is the rise of episodic volunteering really about different values and identities or is this simply the way in which people fit different activities into their busy lives?

\section{Conclusions}

This paper sought to compare how regular and episodic volunteers involved in tourism organisations approached volunteering and fitted this in with their lives. Tourism organisations are very dependent on volunteers in order to deliver both essential and supplementary visitor services, yet research shows that people in Australia are volunteering fewer hours and this is indicative of a changing attitude towards volunteering, moving away from traditional, regular commitments to shorter term volunteer episodes. Extant research has suggested that episodic volunteering is a manifestation of a substantially different approach to volunteering, where participants have different values and expectations from the organisations compared to traditional, regular volunteers.

The regular volunteers in this study did indeed have different motivations from the episodic volunteers and also demonstrated a different level of commitment. The regular volunteers were seeking an ongoing activity, which took up a defined space in their schedule, meeting both a need for social contact and also an opportunity to pursue an interest or passion. In 
contrast, the episodic volunteers were more motivated by doing something worthwhile within the time they had available and being part of a project from start to finish, seeing the outcome.

In this respect, the episodic volunteering in this study represents both a lifestyle choice and a different form of commitment, which is intense rather than long-term. The episodic volunteers were certainly very committed for the time that they were volunteering and this was recognised by the regular volunteers who described the intense volunteer episodes as too hard. Indeed, the level of intensity required for these volunteer episodes is not sustainable for long periods.

The findings demonstrate that both groups of volunteers were time-driven, in that they specifically sought either regular or episodic volunteering to fit into their lifestyle, either as an ongoing or one-off activity. Volunteer motivation theory, such as the VFI used as a framework for analysing the data in this study, has not included time as a motivator but this is clearly a major factor, indeed possibly the most important factor, in how the volunteers in this study selected both the organisation and their role. Future studies of volunteer motivation need to include time as a factor or variable. This finding is valuable to organisations seeking to promote the different volunteer opportunities which they have available.

In today's competitive environment, where volunteer hours per head are in decline, there is a clear need to be flexible. This is reflected by tourism organisations that offer both episodic and regular volunteer roles within their programs, for example, the island tour guides or the airport meet and greeters. The challenge will be for organisations that are unable or unwilling 
to allow volunteers to be flexible. This is compounded by volunteer roles which demand substantial training, such as the zoo volunteers. Clearly, the organisation will want a return on their investment in terms of training but they may need to rethink this if they begin to face a shortage of regular volunteers. It is important that organisations which combine regular and episodic volunteers ensure that they meet both groups' needs in terms of rewards (Hustinx \& Haski-Leventhal, 2009).

The sample sizes in this study are small and the aim of the paper was to examine the phenomena in-depth rather than generalise the findings to the wider population so they must be read as exploratory in nature. The volunteers were also sampled from a range of different organisations, where they undertook different roles. The sampling method was designed to capture a variety of regular and episodic volunteer experiences, however, the different volunteer roles may have substantially influenced the participants' responses rather than the time commitment. This is acknowledged as a limitation in this study. As such this paper also raises several questions for further research. Previous studies have typically questioned respondents about their volunteering at one organisation only. Given that the respondents in this study volunteered at multiple organisations, there is need to investigate the volunteer commitment as part of a portfolio of activities. There is also a need to examine whether episodic volunteers participate in other activities in their lives on an episodic basis, such as work or leisure. This will help uncover whether this complex phenomenon of episodic volunteering is part of a lifestyle choice or simply the only way busy individuals can fit these activities into their lives.

\section{References}


ABS (Australian Bureau of Statistics). (2007). Voluntary Work, Australia 2006. Cat. No. 4441.0. Canberra: ABS.

ABS (Australian Bureau of Statistics). (2011). Voluntary Work, Australia 2010. Cat No. 4441.0 2010. Canberra: ABS

Australian Government. (2010). Intergenerational report 2010: Australia to 2050: Future challenges. Canberra: Australian Treasury.

Australian Government. (2014). National Statement on Ethical Conduct in Human Research 2007 (updated 2014). Canberra: Australian Government, National Health and Medical Research Council, Australian Research Council and Australian Vice-Chancellors' Committee.

Brayley, N., Obst, P., White, K., Lewis, I., Warburton, J. \& Spencer, N. (2014). Exploring the validity and predictive power of an extended volunteer functions inventory within the context of episodic skilled volunteering by retirees. Journal of Community Psychology, 42(1), 1-18.

Brodie, E., Hughes, T., Jochum, V., Miller, S., Ockenden, N. \& Warburton, D. (2011). Pathways through participation: what creates and sustains active citizenship? London: NCVO.

Brudney, J. (Ed). (2005). Emerging Areas of Volunteering. ARNOVA Occasional Paper Series 1(2).

Brudney, J. \& Meijs, L. (2009). It ain’t natural: Toward a new (natural) resource conceptualization for volunteer management. Nonprofit and Voluntary Sector Quarterly, 38(4): 564-581.

Bryen, L., \& Madden, K. (2006). Bounce-back of Episodic Volunteers: What Makes Episodic Volunteers Return? Working Paper No. CPNS 32. Brisbane: Queensland University of Technology. 
Bryman, A. (2004). Social research methods. Oxford: Oxford University Press.

Cabinet Office. (2013). 2012-2013 Community life survey. London: Cabinet Office.

Corporation for National and Community Service. (2014).

http://www.volunteeringinamerica.gov/about.cfm. Accessed 7/7/2014.

77-92.

Evans, E. \& Saxton, J. (2005). The 21st Century volunteer: A report on the changing face of volunteering in the 21 st Century. London: nfpSynergy.

FaHCSIA (Department of, Families, Housing, Community Services and Indigenous Affairs). (2008). Volunteering in Australia: Changing patterns in voluntary work 1995-2006. Canberra, ACT: Commonwealth of Australia.

Gaskin, K. (2003). A choice blend: What volunteers want from organisation and management. London: Institute for Volunteering Research.

Handy, F., Brodeur, N. \& Cnaan, R. (2006). Summer on the island: Episodic volunteering. Voluntary Action, 7(3): 31-46.

Holmes, K. (2008). Changing attitudes towards volunteering and the implications for tourist attractions. In S. Richardson, L. Fredline, A. Patiar \& M. Ternel (Eds.), Tourism and hospitality research, training and practice: 'Where the bloody hell are we?' Proceedings of the $18^{\text {th }}$ annual CAUTHE conference. Queensland: Griffith University.

Holmes, K. (2009). The value of volunteering: the volunteer's story. Australian Journal on Volunteering. 14 (1), 1-9.

Holmes, K. \& Slater, A. (2012). Patterns of participation in voluntary membership associations. Nonprofit and Voluntary Sector Quarterly, 41 (5), 850-869. 
Holmes, K. \& Smith, K. (2009). Managing volunteers in tourism: Attractions, destinations and events. Oxford: Elsevier.

Houle, B., Sagarin, B. \& Kaplan, M. (2005). A functional approach to volunteerism: Do volunteer motives predict task preference? Basic and Applied Social Psychology, 27 (4), 337344.

Hustinx, L., Haski-Leventhal, D. \& Handy, F. (2008). One of a kind: Comparing episodic and regular volunteers at the Philadelphia Ronald MacDonald House. International Journal of Volunteer Administration, 25(3): 50-66.

Hustinx, L. \& Lammertyn, F. (2003). Collective and reflexive styles of volunteering: a sociological modernization perspective. Voluntas, 14(2), 167-187.

Hustinx, L. and Meijs, L.C.P.M. (2011). Re-embedding volunteering: In search of a new collective ground. Vountary Sector Review, 2 (1), 5 - 22.

Jago, L. \& Deery, M. (2002) The role of human resource practices in achieving corporate objectives: An investigation of volunteer use in tourism organisations. International Journal of Contemporary Hospitality Management, 14(5), 229-236.

King, N. (1998). Template analysis. In G. Symon and C. Cassell. (Eds.) Qualitative methods and analysis in organizational research. London: Sage.

King, N. \& Horrocks, C. (2010). Interviews in qualitative research. London: Sage. Kvale, S. \& Brinkman, S. (2009). Interviews. Thousand Oaks: Sage. Low, N., Butt, S., Ellis Paine, A., \& Davis Smith, J. (2007). Helping out: A national survey of volunteering and charitable giving. London: Cabinet Office. 
Macduff, N. (1991). Episodic volunteering: Building the short-term volunteer program.

Walla Walla, Washington: MBA Publishing.

Macduff, N. (2005). Societal changes and the rise of the episodic volunteer. In J. Brudney (Ed). Emerging Areas of Volunteering ARNOVA Occasional Paper Series 1(2).

Mason, J. (2002). Qualitative researching. London: Sage.

McLoughlan, P., Batt, W., Costine, M. \& Scully, D. (2011). Participation in volunteering and paid work. Dublin: European Foundation for the Improvement of Living and Working Conditions

McClintock, N. (2004). Understanding Canadian volunteers: Using the national survey of giving, volunteering and participating to build your volunteer program. Toronto: Canadian Centre for Philanthropy.

Merrill, M. (2006). Global trends and the challenges for volunteering. The International Journal of Volunteer Administration, XXIV(1), 9-14.

Miles \& Huberman (1994). Qualitative Data Analysis: An Expanded Sourcebook. London, Sage publications.

Musick, M. A., \& Wilson, J. (2008). The volunteers: A social profile. Bloomington, Indiana: Indiana University Press.

Nichols, G. \& Holmes, K. (2013). Volunteering as leisure, leisure as volunteering. In. T. Blackshaw (Ed.), The Routledge International Handbook of Leisure Studies. London: Routledge, (456-467).

Office of National Statistics. (2014). Later life in the United Kingdom, June 2014. London: ONS. 
Parker, S. (1997) Volunteering: altruism, markets, careers and leisure. World Leisure and Recreation, 39(3), 4-5.

Pick, D., Holmes, K. \& Brueckner, M. (2011). Governmentalities of volunteering. Voluntas, $22,390-408$

Rochester, C., Ellis Paine, A. \& Howlett, S. (2010). Volunteering and society in the $21^{\text {st }}$ century. London: Palgrave Macmillan.

Rotolo, T. \& Wilson, J. (2007). The effects of children and employment status on the volunteer work on American women. Nonprofit and Voluntary Sector Quarterly, 36(3): 487503.

Smith, K., Baum, T., Holmes, K. \& Lockstone-Binney, L. (2014). Introduction to event volunteering. In K. Smith, L. Lockstone-Binney, K. Holmes and T. Baum (Eds). (2014). Event volunteering: International perspectives on the event volunteering experience. London: Routledge, (pp1-15).

Snyder, M., Clary, E. G., \& Stukas, A. A. (2000). The functional approach to volunteerism. In G. R. Maio \& J. M. Olson, Eds. Why we evaluate: Functions of attitudes. Mahwah, NJ: Erlbaum, pp 365-393.

Stebbins, R. A. (2005) Project-based leisure: theoretically neglect of a common use of free time. Leisure Studies, 24(1), 1-11.

Stebbins, R.A. (2007). Serious leisure: a perspective for our time. New Brunswick, NJ: Transaction Publishers. 
Taylor, T, Mallinson, C. \& Bloch, K. (2008). Looking for a few good women: Volunteerism as an interaction in two organisations. Nonprofit and Voluntary Sector Quarterly, 37(3): 389410.

Tomazos, K. \& Butler, R. (2009). Volunteer tourism: The new ecotourism? Anatolia, 20(1), 196-212.

Volunteering Australia. (2011). National survey of volunteering issues. Melbourne:

Volunteering Australia.

Watson, I., Buchanan, J. Campbell, I. \& Briggs, C. (2003). Fragmented futures: new challenges in working life. Sydney: Federation Press.

Wilson, J. (2012). Volunteerism research: A review essay. Nonprofit and Voluntary Sector Quarterly, 41(2), 176-212.

Winterton, R., Warburton, J., \& Oppenheimer, M. (2013). The future of meals on wheels? Reviewing innovative approaches to meal provision for ageing populations. International Journal of Social Welfare. 22(2), 141-151. 